\title{
PRECAUTIONARY PRINCIPLE SEBAGAI LANDASAN DALAM MERUMUSKAN KEBIJAKAN PUBLIK
}

\author{
Emmy Latifah \\ Fakultas Hukum Universitas Sebelas Maret \\ Email: emmy.latifah@yahoo.com
}

\begin{abstract}
This study aims to explore on how to formulate and what should be considered in formulating the precautionary principle within public policy in order to generate appropriate and effective public policy. Precautionary principle is one of the important principles in International Law, particularly in International Environmental Law. This principle implies caution (prudence) in the face of new challenges, especially in the development of technology. Caution is not understood as an unwillingness to act or lack of courage to face new challenges, but on the contrary, the caution conduct is needed for the policy maker to make the precise decision on a product or a specific activity in which there is a suspicion that a product or an activity contain potential danger to the public but at the same time that danger is not understood because of the lack of scientific evidence.
\end{abstract}

Keywords: precautionary principle, public policy.

\begin{abstract}
Abstrak
Penulisan artikel ini bertujuan untuk mengeksplorasi bagaimana cara merumuskan dan apa saja yang harus dipertimbangkan dalam merumuskan precautionary principle dalam kebijakan publik agar menghasilkan kebijakan publik yang tepat dan efektif. Precautionary principle menjadi salah satu prinsip yang penting di dalam perkembangan Hukum Internasional, khususnya Hukum Lingkungan Internasional. Prinsip ini mengandung makna kehati-hatian dalam menghadapi tantangan baru salah satunya berupa perkembangan teknologi. Sikap kehati-hatian ini bukan dipahami sebagai ketidakmauan untuk bertindak atau kurangnya keberanian untuk menghadapi tantangan baru, namun sebaliknya, sikap kehatihatian bagi para perumus kebijakan publik diperlukan untuk membuat keputusan yang tepat mengenai suatu produk atau kegiatan khusus di mana di dalamnya terdapat kecurigaan bahwa produk atau kegiatan tersebut mengandung potensi bahaya bagi masyarakat luas namun di waktu yang sama bahaya tersebut belum dimengerti karena belum adanya bukti-bukti ilmiah.
\end{abstract}

Kata kunci: precautionary principle, kebijakan publik. 


\section{A. A. Pendahuluan}

Precautionary principle merupakan salah satu prinsip Hukum Internasional yang relatif baru (Lothar Gundling, 1990: 23), yang dijabarkan dalam pernyataan kebijakan publik, kemudian dirumuskan dalam preamble dalam banyak perjanjian internasional (Jaye Ellies, 2006: 448). Prinsip ini berkembang seiring dengan perkembangan teknologi yang sangat pesat, yang tidak dipungkiri, seringkali perkembangan teknologi ini membawa dampak negatif (berbahaya) yang tidak terduga bagi kesehatan masyarakat dan lingkungan. Potensi bahaya yang dihasilkan dari teknologi dan kegiatan manusia dalam rangka pengembangan dan penerapan teknologi ini tidak hanya berskala lokal namun juga global karena produk-produk baru hasil kecanggihan teknologi telah pula didistribusikan oleh perusahaan multinasional dan karenanya dapat membahayakan kesehatan dan integritas fisik dari seluruh populasi dunia dan planet (air, atmosfir, iklim, tanaman, hewan dan manusia) secara ireversibel. Beberapa contoh adanya potensi bahaya dari perkembangan teknologi antara lain dalam hal: mengkonsumsi makanan hasil rekayasa genetik; penggunaan hormon pertumbuhan dalam pemeliharaan ternak; penyakit "sapi gila" ( $\operatorname{mad}$ cow), skandal darah terkontaminasi virus HIV yang terjadi di Perancis; serta klaim kesehatan terkait dengan adanya kandungan phthalates pada PVC (polyvnyl chloride) mainan anakanak (Roberto Andorno, 2004: 11).

Namun demikian, ada pula potensi bahaya yang ditimbulkan dari kemajuan teknologi yang memang muncul atau diharapkan muncul pada beberapa tahun terakhir ini. Contohnya di bidang biomedis, sudah dapat diprediksi tentang adanya potensi bahaya dari teknologi reproduksi seperti ICSI (intracytoplasmic sperm injection) yang diduga dapat menyebabkan kemandulan pada anak yang dikandung (French National Advisory Committeee on Ethics, 2002); xenotransplantation, adalah penggunaan organ hewan untuk tujuan transplantasi pada manusia yang dapat menyebabkan penyakit baru yang tidak dapat terkontrol (US Public Health Service, 2001); kloning manusia dengan menggunakan teknologi transfer nuklir, yang menurut data pada kloning hewan, dapat 
menimbulkan resiko kesehatan pada anak hasil kloning (US National Academy of Science, 2002); serta kemungkinan memodifikasi gen manusia melalui intervensi germline (germline intervention) yang dapat menyebabkan kerusakan permanen pada generasi mendatang (UNESCO International Bioethics Committee, 2003).

Mencermati akan adanya potensi bahaya terhadap kesehatan masyarakat dan lingkungan secara luas yang mungkin ditimbulkan dari perkembangan teknologi dan kegiatan manusia sebagaimana disebutkan di atas, maka dibutuhkan sikap kehati-hatian bagi para perumus kebijakan publik. Sikap kehati-hatian ini bukan dipahami sebagai ketidakmauan untuk bertindak atau kurangnya keberanian untuk menghadapi tantangan baru, namun sebaliknya, sikap kehatihatian bagi para perumus kebijakan publik diperlukan untuk membuat keputusan yang tepat mengenai suatu produk atau kegiatan khusus di mana di dalamnya terdapat kecurigaan bahwa produk atau kegiatan tersebut mengandung potensi bahaya bagi masyarakat luas namun di waktu yang sama bahaya tersebut belum dimengerti karena belum adanya bukti-bukti ilmiah (Wingspread Statement, 1998: 586). Menghadapi resiko yang belum pasti seperti ini, para pembuat kebijakan publik harus menemukan keseimbangan yang memadai (adequate balance) diantara dua kondisi yang ekstrim: di satu sisi, ketakutan yang berlebihan terhadap teknologi baru; dan di sisi lain, adanya sikap yang tidak bertanggung jawab dan pasif terhadap suatu produk atau kegiatan yang benar-benar bisa membahayakan masyarakat luas dan lingkungan hidup (Roberto Andorno, 2004: 11).

Tulisan ini berusaha mengeksplorasi bagaimana cara merumuskan dan apa saja yang harus dipertimbangkan dalam merumuskan precautionary principle dalam kebijakan publik agar menghasilkan kebijakan publik yang efektif.

\section{B. Metode Penelitian}

Tulisan ini merupakan hasil dari penelitian hukum normatif, yang mengkaji asas hukum (Soerjono Soekanto dan Sri Mamuji, 2007: 13-14), yaitu precautionary principle. Data yang digunakan adalah data sekunder, yaitu berupa bahan hukum primer, bahan hukum sekunder dan bahan hukum tersier. Bahan hukum primer terdiri atas semua produk hukum, baik nasional maupun 
internasional; bahan hukum sekunder terdiri atas jurnal-jurnal, baik jurnal nasional maupun jurnal internasional yang berhubungan dengan tema yang dikaji, sedangkan bahan hukum tersier berupa kamus. Semua data diperoleh melalui studi pustaka. Penelitian terhadap asas hukum precautionary principle dianalisis melalui penafsiran terhadap peraturan perundang-undangan dan melalui sistematika hukum, dalam hal mempertanyakan apakah berbagai kaedah hukum yang dikaji dalam peraturan perundang-undangan memang berasal dari asas precautionary principle, melalui metode analogi dan penghalusan (Soerjono Soekanto, 2008: 252).

\section{Hasil Penelitian dan Pembahasan}

\section{Definisi dan Unsur-unsur Precautionary Principle}

Secara etimologi, istilah "precaution" berasal dari Bahasa Latin "prae" yang berarti "sebelum", dan "cautio" yang berarti "security" atau "keamanan". Istilah "caution" dalam Black's Law Dictionary diartikan sebagai: (1) "security given to ensure performance of some obligation"; dan (2) "the person who gives the security" (Bryan A. Garner, 1999: 214). Secara umum, precautionary principle dapat diartikan sebagai suatu prinsip tindakan kehati-hatian yang dilakukan sebelum timbulnya dampak.

Bukan perkara yang mudah untuk memberikan definisi precautionary principle yang berlaku universal dan bermakna lebih dari "take care" (Christopher D. Stone, 2001) ataupun "better safe than sorry" (Frank Cross, 1996: 851). Namun karena prinsip ini telah mengalami evolusi, maka ia telah pula mendapatkan substansi dan dimensi.

Pertama kalinya precautionary principle dirumuskan dalam peraturan perundang-undangan adalah ketika prinsip ini dimasukkan dalam Program Perlindungan Lingkungan Jerman Tahun 1971 (the German Program of Environmental Protection of 1971), dengan istilah "vorsorge". Program ini menghasilkan berbagi macam peraturan perundang-undangan terkait perlindungan lingkungan di Jerman, dan precautionary principle menjadi salah satu prinsip yang digunakan di dalam serangkaian peraturan tersebut. Dari Jerman, prinsip ini 
menyebar ke sistem hukum negara-negara Eropa seperti Denmark (tercantum di dalam Consolidate Act of Denmark No. 583 of July 9, 1993), di Swedia (sebagai prinsip umum di dalam Environmental Code of 1999), dan di Perancis (Di Perancis, prinsip ini diperkenalkan pertama kali dalam the Rural Code Pasal 200201 melalui "Loi Barnier"/Barnier Act pada tanggal 2 Februari 1995, dan kemudian dimasukkan ke dalam the French Environmental Code of 2000). Prinsip ini tidak hanya berkaitan dengan Hukum Lingkungan, namun juga terkait dengan isu-isu ketahanan pangan dan kesehatan masyarakat. Selanjutnya, sejak dimasukkannya prinsip ini ke dalam Maastricht Treaty 1992, prinsip ini kemudian menjadi salah satu pilar dalam Hukum Lingkungan Uni Eropa bersamaan dengan prinsip pencegahan (the prevention principle), prinsip perbaikan kerusakan (the principle of rectifying damage), dan prinsip "the polluter-pays".

Sebagaimana telah disebutkan sebelumnya bahwa precautionary principle awalnya digunakan sebagai salah satu prinsip di Jerman dalam Program Perlindungan Lingkungan tahun 1971 dengan istilah "vorsorge". "Vorsorge" berarti "foresight" (pandangan yang jauh ke depan), sementara "vorsorgeprinzip" artinya "foresight principle" (prinsip mengenai pandangan jauh ke depan). Konsep awal precautionary principle di Jerman ini memberi pengertian bahwa masyarakat harus berusaha untuk menghindari kerusakan lingkungan melalui "sikap hati-hati" dalam hal perencanaan yang bersifat "looking forward", dan menghalangi aktivitas yang memiliki potensi bahaya. "Vorsorgeprinzip" dijadikan landasan dalam menyusun kebijakan untuk mengatasi pencemaran sungai, hujan asam, pemanasan global dan polusi di Laut Utara (North Sea) (Raffensberger and Tickner, 1999: 4).

Sementara itu, di dalam Undang-Undang Perancis, precautionary principle didefinisikan sebagai:

"...the principle according to which the absence of certainty, taking account of current scientific and technical knowledge, ought not to delay the adoption of effective and proportionate measures aimed at preventing a risk or serious and irreversible damage to the environment, at an economically acceptance cost." 
Pada tingkat global, precautionary principle diadopsi di dalam banyak perjanjian internasional. Perjanjian internasional pertama yang mengadopsi prinsip ini adalah the Ministerial Declaration on Protection of the North Sea (November 1987) (selanjutnya disebut Declaration of North Sea), pada Paragraf VII menyatakan bahwa:

“...in order to protect the North Sea from possibly damageing effects of the most dangerous substance, a precautionary approach is necessary which may require action to control inputs of such substances even before a causal link has been established by absolutely clear scientific evidence."

Convention for Protection of the Marine Environment of the Baltic Sea Area 1992 (selanjutnya disebut Helsinki Convention) merumuskan precautionary principle sebagai berikut:

“...applying the precautionary principle, i.e, to take effective action to avoid pottentially damaging impacts of substances that are persistent, toxic and liable to bioaccumulate even where there is a lack of full scientific certainty to prove a causal link between emissions and effects."

Sementara the 1992 United Nations Conference on Environment and Development (Rio Declaration) pada Prinsip ke-15 menyatakan tentang precautionary principle sebagai berikut.

"...where there are threats of serious or irreversible damage, lack of full scientific certainty shall not be used as a reason for postponing costeffective measures to prevent environmental degradation. “

Masih banyak lagi perjanjian internasional yang mengadopsi precautionary principle dan merumuskannya menjadi kebijakan publik. Memperhatikan beberapa definisi precautionary principle, baik yang dijabarkan dalam peraturan perundang-undangan nasional maupun di dalam instrumen hukum internasional, tampak bahwa formulasi precautionary principle tidaklah seragam. Namun demikian, terdapat unsur-unsur yang sama yang terkandung di dalam precautionary principle. Unsur-unsur tersebut adalah sebagai berikut. 


\section{a. Adanya ketidakpastian risiko (uncertainty of risk)}

Adanya ketidakpastian resiko merupakan salah satu unsur penting dalam precautionary principle. Bagi banyak kalangan, masih terdapat kesalahpahaman dalam membedakan antara "precautionary measures" (tindakan hati-hati) dengan "preventive measure" (tindakan pencegahan). Precautionary measures memiliki arti yang melampaui preventive measures. Berkaitan dengan ketidakpastian resiko, dalam kasus preventive measure, bahaya atau resiko yang terkandung dalam sebuah produk atau aktivitas itu sudah diketahui, misalnya merokok, penggunaan pestisida, serta kapan dan dalam situasi seperti apa kerusakan akibat penggunaan produk atau melakukan aktivitas tertentu tersebut sudah dapat diketahui. Sebaliknya, precautionary measures dilakukan sebelum diketahui adanya hubungan sebab akibat antara teknologi yang ada pada suatu produk atau kegiatan dengan potensi kerusakan atau bahaya yang akan ditimbulkan karena belum adanya bukti ilmiah (Roberto Andorno, 2004: 17). Ini berarti bahwa precautionary measures sangat relevan dilakukan hanya jika potensi resiko atau bahaya yang terkandung pada sebuah produk atau aktivitas tidak dapat sepenuhnya ditunjukkan karena data ilmiah tidak mencukupi atau tidak meyakinkan (Vern R. Walker, 1991: 570).

\section{b. Adanya penilaian ilmiah atas potensi risiko yang ditimbulkan (scientific assesment of risk)}

Meskipun precautionary principle diterapkan pada konteks ketidakpastian bukti ilmiah terhadap potensi risiko yang ditimbulkan, namun pelaksanaan prinsip ini harus tetap dimulai dengan penilaian ilmiah secara lengkap dan jika memungkinkan, juga dilakukan identifikasi terhadap setiap derajat dari kondisi ketidakpastian ilmiah atas potensi resiko yang akan ditimbulkan tersebut (Caroline E. Foster, 2011: 154).

Tujuan dari unsur yang kedua ini adalah dalam rangka untuk mencegah terjadinya penyalahgunaan precautinary principle, misalnya untuk melakukan tindakan proteksi yang berlebihan (René von Schomberg, 2012: 148-149). Oleh sebab itu maka segala potensi risiko yang mungkin akan ditimbulkan oleh suatu 
produk atau aktivitas yang kiranya dapat mengganggu kesehatan masyarakat dan lingkungan harus ditentukan terlebih dahulu oleh para pakar yang memiliki kompetensi berdasarkan prinsip-prinsip ilmiah. Dalam hal ini, pelaksanaan preacutionary principle menuntut pemisahan fungsional yang jelas antara mereka yang bertanggung jawab melakukan penilaian terhadap potensi resiko (risk assessment) dengan pengambil keputusan yang terkait kebijakan publik (risk management) dengan melibatkan para pemangku kepentingan baik langsung maupun tidak langsung terlibat dalam suatu masalah seperti konsumen dan perwakilan industri (Jaye Ellis, 2006: 451).

\section{c. Adanya potensi kerusakan serius atau permanen (potential for serious or irreversible damage)}

Terkait dengan elemen ketiga, yaitu adanya potensi kerusakan serius (serious damage) atau kerusakan permanen (irrevesible damage), perlu terlebih dahulu dibedakan antara keduanya. Sebuah kerusakan dikatakan serius (serious damage) jika kerusakan tersebut berdampak terhadap: kehidupan dan kesehatan individu; sumber daya alam yang vital (seperti air, tanah, udara); kelestarian spesies; iklim; dan keseimbangan ekosistem (Robert Andorno, 2004: 18). Namun demikian, yang menjadi masalah adalah bagaimana menentukan ukuran ambang batas kerusakan sangat tergantung pada budaya masyarakat setempat sehingga langkah-langkah yang bersifat precautionary dapat dilaksanakan. Kepunahan suatu spesies di satu wilayah belum tentu dianggap sebagai kerusakan serius di wilayah lain. Hal ini terutama sangat bergantung pada apakah suatu produk atau aktivitas yang mengandung teknologi baru akan membawa manfaat yang besar terhadap masyarakat atau tidak (Robert Andorno, 2004: 18).

Sementara itu, kerusakan disebut permanen (irreversible damage) ketika kerusakan yang terjadi melibatkan sumber daya lingkungan yang tidak tergantikan, atau bisa dikembalikan namun memelukan jangka waktu yang cukup lama atau dengan biaya yang besar (Steven R. Dovers and John W. Handmer, 1999: 172). Dengan kata lain, kerusakan yang bersifat permanen termasuk dalam kategori kerusakan serius, namun kerusakan serius tidak selalu merupakan 
kerusakan permanen. Misalnya saja pencemaran air laut yang disebabkan karena adanya tumpahan minyak bukan termasuk kategori kerusakan permanen, namun tidak diragukan lagi keseriusannya. Oleh sebab itu, alternatif kedua kriteria ini diakomodasi (mendapat pembenaran) dalam pelaksanaan precautionary principle. Selain itu, di beberapa kasus, precautionary principle juga diimplementasikan pada kondisi di mana bahaya atau kerusakan dianggap tidak serius atau tidak permanen dalam jangka pendek, namun dapat menjadi kerusakan serius dan permanen pada jangka panjang sebagai hasil akumulasi dampak dari kegiatan atau produk yang tampaknya tidak berbahaya.

Terkait dengan elemen ketiga ini, jika suatu bahaya memiliki satu dari dua karakteristik ini, yaitu: (1) intensitas yang tinggi atau lingkup geografis; (2) skala waktu yang lama; maka precautionary principle dapat diterapkan (Daniel Bodansky, 2004: 387).

\section{d. Adanya langkah-langkah pencegahan yang proporsional}

Persyaratan "proporsional" di sini berarti bahwa tidak setiap kondisi adanya potensi risiko membenarkan setiap tindakan kehati-hatian (precautionary measures). Precautionary measure hanya dilakukan dengan terlebih dahulu mempertimbangkan dampaknya terhadap masyarakat. Persyaratan ini memiliki ruang lingkup yang lebih luas dibanding dengan persyaratan klasik "cost-benefit analysis" berdasarkan kriteria ekonomi (Gregory N. Mandel and James Thuo Gathii, 2006: 1044). Precautionary measures lebih mengutamakan perlindungan kesehatan masyarakat dan lingkungan dibanding dengan kepentingan ekonomi. Namun demikian, pendekatan ini tidak kemudian mengesampingkan pemeriksaan dari keseluruhan biaya untuk masyarakat. Ada banyak contoh precauationary measures yang dapat dilakukan oleh pengambil kebijakan misalnya mengurangi keterpaparan (reduction of exposure), pemantauan, pelabelan, uji coba sebelum masuk pasar, dan melakukan kajian atau penelitian untuk mengurangi ketidakpastian. Melarang suatu produk atau kegiatan harus menjadi pilihan terakhir, yaitu ketika potensi kerusakan dirasa sangat serius dan kemungkinan terjadinya sangat besar (Lucas Bergkamp, 2002: 19). Dalam kasus apapun, 
keputusan yang didasarkan pada precautionary principle harus bersifat sementara (provisional), yang berarti bahwa keputusan tersebut harus terus dikaji secara aktif dan informasi yang dihasilkan harus diperbarui lebih lanjut sehingga mengurangi ketidakpastian risiko.

\section{e. Adanya pergeseran beban pembuktian}

Secara tradisional, hukum pembuktian menyatakan bahwa pemerintah (otoritas publik) harus menunjukkan alasan yang masuk akal dan berdasarkan bukti ilmiah untuk membatasi (atau melarang) penjualan suatu produk atau aktivitas yang berkaitan dengan pengembangan teknologi baru. Ini artinya bahwa sebuah teknologi dapat terus diimplementasikan hingga ia terbukti bersalah. Sepanjang belum terbukti bersalah (berdasarkan bukti ilmiah), maka produk hasil teknologi dapat terus dijual misalnya, atau kegiatan yang berkaitan dengan pengembangan teknologi baru dapat terus dilanjutkan.

Sebaliknya, precautionary principle ini menawarkan pendekatan yang berbeda dalam hal pembuktian. Precautionary principle mengusulkan pergeseran beban pembuktian dengan menggunakan pendekatan beban pembuktian terbalik terhadap suatu produk atau kegiatan yang memiliki potensi risiko yang mengancam kesehatan masyarakat dan lingkungan. Dalam hal ini, beban pembuktian akan ditanggung oleh pencipta teknologi. Para pencipta teknologi harus dapat membuktikan bahwa teknologi baru yang mereka ciptakan tidak berbahaya (zero risk). Pergeseran beban pembuktian ini harus dipahami dalam konteks bahwa pencipta teknologi harus menunjukkan bahwa ia telah melakukan penelitian yang diperlukan untuk menyediakan tingkat toleransi risiko hingga pada kesimpulan bahwa produk atau kegiatan mereka menawarkan tingkat keamanan yang dapat diterima oleh masyarakat dan lingkungan (Monika Ambrus, 2012: 259-270). Selanjutnya, menjadi tanggung jawab politik para pembuat kebijakan untuk memutuskan tindakan apa yang tepat dengan mempertimbangkan hasil-hasil penelitian dari para ahli atau badan khusus yang diberi tugas untuk melakukan penelitian mengenai potensi resiko tersebut (Robert W. Hahn and Cass 
R. Sunstein, 2005: 6).

Beban pembuktian terbalik ini dibenarkan karena para pencipta teknologi adalah pihak akan mendapatkan manfaat secara ekonomi dari produk atau kegiatan yang akan dilakukannya. Sebaliknya, masyarakat sebagai pengguna juga memiliki hak untuk terlindungi dari potensi bahaya yang mungkin akan ditimbulkan (Katie Steele, 2006: 25). Pergeseran ini memiliki keuntungan praktis yang penting karena produsen (pencipta teknologi) berada pada posisi yang terbaik untuk dapat menyelesaikan masalah yang timbul dari adanya kegiatan mereka. Selain itu, beban pembuktian terbalik juga dapat digunakan sebagai mekanisme untuk meminimalkan potensi risiko (Carl. F. Cranor, 1999: 86). Dengan kata lain, jika ada suatu teknologi atau aktivitas baru yang menawarkan keuntungan, mereka dapat diperkenalkan kepada masyarakat jika memenuhi beban pembuktian yang disyaratkan oleh precautionary principle (Jon M. Van Dyke, 2004: 377).

\section{Fungsi Perumusan Precautionary Principle dalam Kebijakan Publik}

Secara garis besar, precautionary principle diformulasikan dalam kebijakan publik melalui dua cara yaitu cara negatif dan positif. Formulasi precautionary principle melalui cara negatif digunakan untuk mengecualikan pembenaran tertentu untuk "tidak bertindak", atau dapat pula digunakan sebagai lisensi (izin) untuk melakukan suatu tindakan, namun tidak memerlukan tindakan pencegahan. Sementara cara postif dilakukan dengan merumuskan tindakantindakan kehati-hatian. Menurut Daniel Bodansky, ada tiga fungsi rumusan precautionary principle dalam kebijakan publik, yaitu (Daniel Bodansky, 2004: 383-386)

\section{a. Precautionary principle sebagai dasar untuk tidak menunda aksi} lingkungan yang disebabkan oleh ketidakpastian bukti ilmiah

Pada awalnya, perjanjian internasional cenderung melakukan suatu aksi lingkungan (bisa berupa konservasi, management measures, dan lain sebagainya) 
didasarkan pada bukti ilmiah. Salah satu contohnya terdapat pada Pasal 44(4) Paris Convention for the Prevention of Marine Pollution from Land-Based Sources 1974 merumuskan bahwa: “...if scientific evidence has established that a serious hazard may be created... and if urgent action is necessary". Seiring perkembangan teknologi, precautionary principle menolak konsep bahwa aksi lingkungan harus menunggu bukti ilmiah. Hal ini terlihat pada Prinsip ke-15 Rio Declaration on Environment and Development yang menyatakan bahwa: “...lack of scientific certainty shall not be used as a reason for postponing cost-effective measures to prevent environmental degradation." Beberapa formulasi yang mirip juga ditemukan dalam perjanjian internasional yang lain, seperti:

1) Bagian preamble Convention on Biological Diversity, yang menyatakan bahwa "...where there is threat of significant reduction or loss of biological diversity, lack of full scientific certainty should not be used as a reason for postponing measures to avoid or minimize such a threat."

2) Pasal 6(2) the Straddling Stock Convention, yang menyatakan bahwa “...the absense of adequate scientific information shall not be used as a reason for postponing or failing to take conservation and management measures."

3) Keputusan yang dibuat oleh the Ninth Conference of Parties to the Convention on International Trade in Endangered Species, yang menyatakan bahwa "...scientific uncertainty shall not be used as a reason for failing to act in the best interest of concervation of the species".

Berdasarkan formulasi precautionary principle di beberapa instrumen internasional di atas terlihat bahwa prinsip ini tidak menciptakan suatu kewajiban afirmatif (affirmative duty) untuk mengambil tindakan yang bersifat precaution (precaution measures). Jikalaupun suatu negara tidak mengambil aksi lingkungan tertentu karena alasan lain, negara tersebut tidak boleh menggunakan "ketidakpastian bukti ilmiah" sebagai alasan untuk tidak bertindak.

\section{b. Precautionary principle sebagai lisensi untuk bertindak}

Precautionary principle dalam konteks perdagangan memiliki fungsi sebagai lisensi untuk bertindak (precautionary as a license to act). Akibatnya, 
prinsip ini memberikan justifikasi atau pembenaran untuk melakukan aksi-aksi lingkungan yang disamarkan sebagai hambatan perdagangan. Hal ini terlihat pada rumusan Pasal 11.8 Cartagena Protocol on Biosafety of 2000 yang menyatakan bahwa "...lack of scientific certainty due to insufficient relevant scientific information and knowledge ... shall not prevent that Party from taking a decision,... in order to avoid or minimize such potential adverse effects." Oleh sebagian negara, Pasal ini digunakan sebagai pembenaran untuk mengenakan pembatasan impor organisme hasil modifikasi yang sebenarnya tindakan pembatasan ini bertentangan dengan Perjanjian WTO mengenai Sanitary and Phytosanitary Measures (SPS Agreement). SPS Agreement mengharuskan negara untuk mendasarkan ketentuan SPS dalam melakukan penilaian resiko (Pasal 5.1) dan dalam menerapkan ketentuan SPS tersebut hanya sejauh yang diperlukan untuk melidungi kesehatan dan kehidupan manusia, hewan,dan tumbuhan (Pasal 2.2).

Berdasarkan rumusan precautionary principle di dalam Biosafety Protocol ini dapat dikatakan bahwa preacutionary principle tidak memerlukan negara pengimpor untuk mengenakan pembatasan. Apakah negara pengimpor akan melakukan pembatasan adalah murni kebijakan negara tersebut sendiri. Precautionary principle hanya berusaha untuk menghapus hambatan hukum yang mungkin ada.

Contoh kasus yang sangat fenomenal terkait dengan precautionary principle dalam SPS Agreement adalah kasus Beef Hormones, di mana Uni Eropa membenarkan larangan impor daging sapi (impor dari Amerika Serikat) yang dihasilkan dari sapi yang telah disuntik hormon pertumbuhan. Meskipun Uni Eropa tidak dapat membuktikan secara ilmiah bahwa hormon pertumbuhan sapi dapat menimbulkan ancaman bagi kesehatan manusia, namun Uni Eropa berusaha membenarkan tindakan larangan tersebut berdasarkan alasan precautionary principle yaitu berkaitan dengan tidak adanya bukti atau kepastian ilmiah, suatu negara dibenarkan untuk melakukan suatu tindakan. Sementara Badan Banding WTO (appellate body) menolak pendapat Uni Eropa yang membenarkan tindakan pembatasan impor yang tidak konsisten dengan aturan perdagangan internasional. 
SPS Agreement sendiri sebenarnya memungkinkan suatu negara mengambil suatu tindakan (precautionary measures), atas dasar sementara, dalam menghadapi ketidakpastian ilmiah.

\section{c. Precautionary principle sebagai dasar timbulnya kewajiban untuk bertindak}

Fungsi lain dari precautionary principle adalah menciptakan kewajiban untuk bertindak (precautionary principle as a duty to act). Hal ini terlihat pada Pasal 3(2) Helsinski Convention yang menyatakan:

“...shall ... take preventative measures when there is a reason to assume that substances or energy introduced, directly or indirectly, into the marine environment, may create hazards to human health, harm living resources and marine ecosystems, damage amenities or interfere with other legitimate uses of the seas even when there is no conclusive evidence of a causal relationship between inputs and their alleged effects."

Beberapa rumusan lain dari precautionary principle yang terdapat dalam perjanjian internasional menciptakan kewajiban yang lebih spesifik. Hal ini terlihat misalnya di dalam resolusi yang diadopsi oleh Paris Convention for the Prevention of Marine Pollution from Land-Based Sources yang menyatakan bahwa ketika ambang batas bahaya telah terlampaui, maka negara berkewajiban untuk menggunakan "teknologi terbaik" (the best available technology) untuk mengurangi emisi polusi. Hal yang sama juga dirumuskan di dalam Paragraf 11 the World Charter of Nature. The Bamako Convention on the Ban of the Import into Africa and the Control of Transboundary Movement and Management of Hazardous Wastes within Africa berisi kewajiban untuk menyediakan metode produksi yang ramah lingkungan (clean production methods) yang dibebankan kepada para pihak untuk mencegah zat-zat berbahaya mengkontaminasi alam.

\section{Beberapa Hal yang Perlu dipertimbangkan dalam Merumuskan Precautionary Principle dalam Kebijakan Publik}

Menurut Hickey, ada lima hal yang perlu dipertimbangkan dalam merumuskan precautionary principle dalam kebijakan publik. Kelima hal tersebut 
adalah: (a) adanya pernyataan tujuan lingkungan hidup; (b) ditetapkannya ruang lingkup penerapan precautionary principle; (c) mengidentifikasi kegiatan atau aktivitas yang memerlukan kehati-hatian; (d) macam-macam precautionary measures yang diperlukan; (e) penerapan norma-norma (James E. Hickey Jr and Vern R. Walker, 1995: 440-453). Berikut penjelasannya.

\section{a. Adanya Pernyataan Tujuan Lingkungan Hidup (statement of environmental goals)}

Sebuah pernyataan tujuan lingkungan hidup sangat diperlukan dalam merumuskan precautionary principle dalam kebijakan publik karena mengandung beberapa fungsi. Pertama, sebuah pernyataan tujuan lingkungan hidup berfungsi sebagai cita-cita bersama yang hendak diwujudkan oleh para pihak dalam perjanjian internasional (pada tingkat global) maupun bagi setiap pemangku kepentingan (pada tingkat nasional). Pernyataan tujuan ini berisi visi global yang direfleksikan dalam bentuk larangan dan mandat. Contoh pernyataan tujuan lingkungan hidup yang cukup spesifik dan informatif misalnya: untuk mengurangi atau menghapus penyebab pencemaran lingkungan (biasanya disebabkan karena aktivitas manusia) yang dapat mengakibatkan perubahan iklim, menipisnya lapisan ozon, ataupun mengurangi atau menghapus kegiatan manusia yang berdampak pada kerusakan lingkungan laut. Pernyataan tujuan lingkungan hidup dapat membantu para pihak untuk menafsirkan ketentuan di dalam perjanjian internasional atau untuk menyelesaikan sengketa maupun dalam hal penegakan hukum. Selain itu, pernyataan ini juga berfungsi sebagai informasi kepada negara lain yang bukan merupakan pihak atau pemangku kepentingan dalam perjanjian internasional ataupun hukum nasional.

Kedua, pernyataan tujuan lingkungan hidup ini berfungsi untuk menghindari biaya (cost) atas adanya kerusakan lingkungan. Pernyataan tujuan lingkungan hidup harus memperhitungkan aspek lingkungan hidup saja. Pernyataan tersebut harus menggambarkan keadaan akhir lingkungan hidup yang diinginkan. Jika para pihak dapat fokus pada tujuan lingkungan hidup yang telah menjadi cita-cita bersama, maka para pihak menjadi lebih mudah untuk mencapai tujuan bersama tersebut. Pada akhirnya, jika tujuan lingkungan hidup dapat 
diwujudkan secara bersama, maka para pihak akan terhindar dari biaya atas kerusakan lingkungan.

Deklarasi Rio mengilustrasikan bagaimana kepentingan politik dan ekonomi dapat menyebabkan pernyataan tujuan lingkungan hidup menjadi tidak informatif. Deklarasi Rio merumuskan precautionary principle dalam rangka "...protect the integrity of the global environmental and development system...recognizing the integral and interdependent nature of the Earth, our home...”. Walaupun pernyataan ini bersifat universal, dapat diterima oleh entitas politik, ekonomi dan budaya, namun pernyataan ini kurang detail dan tidak jelas dalam merumuskan tujuan lingkungan hidup yang diharapkan dari adanya kesepakatan yang tertuang dalam Deklarasi Rio. Para pihak seharusnya menyetujui secara detail tujuan lingkungan hidup serta kapan dan bagaimana caranya precautionary principle dapat dikonkritkan dalam serangkaian usaha guna mencapai tujuan yang hendak dicapai.

\section{b. Ruang Lingkup Penerapan Precautionary Principle}

Ruang lingkup penerapan preacuationary principle biasanya ditetapkan berdasarkan keadaan geografis atau berdasarkan berdasarkan aspek ekosistem yang akan dilindungi. Contoh ruang lingkup penerapan precautionary principle yang didasarkan pada kondisi geografis adalah North Sea Declaration yang ruang lingkup berlakunya hanya di Laut Utara. Selain itu, Bamako Convention juga memiliki ruang lingkup berlakunya precautionary principle hanya di kawasan Afrika saja. Sementara contoh ruang lingkup precautionary principle yang didasarkan pada aspek ekosistem yang akan dilindungi sebagaimana tercantum di dalam Montreal Protocol adalah lapisan ozon, Declaration of the Second World Climate Change Conference ruang lingkupnya adalah perubahan iklim, dan Final North Sea Declaration memiliki ruang lingkup perlindungan di lingkungan laut.

Selanjutnya, para pihak dapat memperjelas atau membatasi ruang lingkup berlakunya precautionary principle dengan mengidentifikasi jenis kerusakan (type of harm) maupun jenis ancaman (type of hazard). Jenis kerusakan yang harus dihindari misalnya "penipisan lapisan ozon", "eutrofikasi atau pengasaman" atau dengan menggunakan istilah yang lebih umum misalnya "kerusakan permanen di 
lingkungan laut". Sementara, pembatasan berdasarkan jenis ancaman misalnya dapat dirumuskan seperti "untuk melindungi lapisan ozon dari zat tertentu seperti chlorofluorocarbons (CFCs)", "mencegah perubahan iklim yang disebabkan karena gas rumah kaca" atau "untuk melindungi kawasan Afrika dari limbah berbahaya".

Penetapan ruang lingkup sangat penting dalam hukum internasional karena beberapa alasan: (1) ruang lingkup akan sangat berkaitan degan kedaulatan negara; (2) berkaitan dengan yurisdiksi negara; dan (3) berkaitan dengan standar penilaian secara objektif yang dilakukan oleh negara (pihak) lain berkenaan dengan komitmen suatu negara (pihak tertentu) terhadap pelaksanaan precautionary principle yang dirumuskan dalam perjanjian internasional atau peraturan perundang-undangan nasional.

\section{c. Identifikasi Kegiatan-kegiatan yang Mensyaratkan Precaution} Measues

Setiap perumusan precautionary principle harus secara jelas mengidentifikasi kegiatan-kegiatan manusia yang membutuhkan precautionary measures (tindakan kehati-hatian), misalnya saja pembuangan limbah padat, pemakaian zat cair berbahaya, memancarkan polusi udara, ataupun mengangkut zat-zat berbahaya. Identifikasi ini penting dilakukan agar para pihak (pemerintah dan para pemangku kepentingan) dapat merencanakan kegiatan-kegiatan mereka sehingga tidak melanggar tujuan lingkungan hidup. Hal ini juga akan berdampak pada denda dan biaya yang harus dikeluarkan oleh para pihak jika sampai mereka melanggar tujuan lingkungan hidup. Ketidakjelasan kegiatan-kegiatan yang memerlukan precautionary measures dapat menciderai tujuan lingkungan hidup yang telah menjadi cita-cita bersama karena akan menciptakan kemungkinan ketika suatu kegiatan tidak diketahui masuk kategori kegiatan yang membutuhkan precautionary measures hingga ancaman lingkungan hidup terjadi.

Kegiatan yang harus diidentifikasi dapat dikategorikan menjadi dua jenis, yaitu: (1) berdasarkan enumerasi (disebutkan satu per satu); (2) berdasarkan dampaknya. Berdasarkan enumerasi misalnya the Bamako Convention menyebutkan jenis limbah berbahaya (catagories of wastes which are hazardous 
wastes) pada Annex I dan Pada Annex II memberi daftar jenis-jenis bahaya (list of hazardous characteristic). Sementara kategori kegiatan yang dikelompokkan berdasarkan dampaknya dapat dibagi tiga tipe: (a) berdasarkan efek sampingnya; (b) berdasarkan jenis kondisi yang dapat menyebabkan timbulnya efek samping; dan (c) berdasarkan tingkat keyakinan (degree of confidence) sehingga precautionary measures dibutuhkan.

\section{d. Jenis Precautionary Measures}

Setidaknya ada empat hal yang perlu dipertimbangkan dalam menentukan tindakan yang bersifat precautionary, yaitu: (1) procedural requirements; (b) study requirement; (c) substantive standard; (d) other actions.

Procedural requirements biasanya berkaitan dengan prosedur tertentu sebelum precautionary measures dilakukan. Misalnya kewajiban untuk melakukan notifikasi (pemberitahuan), syarat perizinan, penerbitan lisensi (izin) untuk melakukan suatu tindakan, ataupun persyaratan pelaporan.

Study requirements adalah kegiatan mengumpulkan informasi yang guna mengurangi ketidakpastian bukti ilmiah yang dapat menyebabkan kerusakan lingkungan. Dalam hal ini, study requirements meliputi pengumpulan informasi mengenai persediaan emisi, mempersiapkan penilaian dampak lingkungan (risk assessment) maupun memantau dampak dari kegiatan-kegiatan yang telah diidentifikasi membutuhkan precautionary measures.

Substantive standards harus ditetapkan sebelum kegiatan yang membutuhkan precautionary measures dilakukan. Standar substansi harus mencerminkan besarnya resiko yang ditimbulkan dari kegiatan tersebut. Jika resiko kerusakan lingkungan besar, maka standar substansinya dapat menggunakan "the best available technology" untuk mengurangi emisi misalnya, atau menggunakan standar substansi berupa pembebanan pembuktian atas kegiatan yang akan dilakukan. Selain itu, standar substansi juga harus mengidentifikasi tingkat kepercayaan (high degree of confidence) yang tinggi bahwa kegiatan yang akan dilakukan memenuhi standar tersebut.

Other action berkaitan dengan kewajiban para pihak dalam melaksanakan rumusan precautinary principle untuk melakukan kegiatan lainnya 
seperti "meningkatkan aliran modal dan penggunakan teknologi yang ramah lingkungan kepada negara-negara miskin" atau "berkomitmen untuk menyepakati perjanjian internasional lainnya yang juga mengandung rumusan precautionary principle."

\section{e. Perumusan Kriteria yag Baik}

Perumusan kriteria yang baik akan sangat menentukan keberhasilan implementasi sebuah aturan dan tercapainya tujuan. Salah satu contoh perjanjian internasional yang sangat baik dalam merumuskan kriteria-kriteria adalah the North Sea Declaration. Tujuan lingkungan hidup yang terdapat dalam Deklarasi ini adalah “...avoiding potentially damaging impact of substances that are persistent, toxic and liable to bioaccumulate". Ruang lingkup penerapan precautionary principle berdasarkan atas kondisi geografis, aktivitas yang termasuk dalam kategori yang memerlukan precautionary measures meliputi operasi pabrik pengolahan limbah kota, pembuangan limbah lumpur di laut, dan melakukan pembakaran di laut. Precautionary measures yang disyaratkan termasuk: "mengurangi polusi secara signifikan dengan menggunakan the best available technology", "mencegah polychlorinated biphenyls (PCBs) masuk ke lingkungan laut", maupun "mengurangi resiko hilangnya barang kemasan di laut dengan menerapkan kode maritim internasional khusus untuk transportasi barang".

\section{Simpulan}

Berbagai formulasi precautionary principle dalam banyak instrumen hukum internasional dan nasional menandakan bahwa prinsip ini masuk dalam kualifikasi "high-order legal principle" yang digunakan sebagai dasar perumusan kebijakan publik secara umum maupun hukum tertentu yang bersifat lebih khusus. Dari berbagai perjanjian internasional yang dibuat dengan mendasarkan pada precautionary principle, ada beberapa hal yang masih perlu dipertimbangkan untuk diatur lebih lanjut di kemudian hari jika ingin merumuskan kebijakan publik yang lebih tepat dan lebih efektif lagi. 


\section{Daftar Pustaka}

\section{Buku:}

Bodanky, Daniel. 2004. Deconstruction the Precautionary Principle, dalam D.D. Caron and H.N Scheiber (Eds), Bringing New Law to Ocean Water, Netherland: Koninklijke Brill NV.

Cranor, Carl. F. 1999. Asymmetric Information, the Precautionary Principle, and Burdens of Proofs, dalam Carolyn Raffensperger and Joel A. Tickner, Protecting Public Health and the Environment: Implementing the Precautionary Principle, Washington DC: Island Press.

Dovers, Steven R. and John W. Handmer. 1999. Ignorance, Sustainability, and the Precautionary Principle: Toward an Analytical Framework, dalam R. Harding and E. Fisher (Eds), Perspectives on the Precautionary Principle, Leichhardt, New South Wales: The Federation Press.

Foster, Caroline E. 2011. Science and the Precautionary Principle in International Court and Tribunal: Expert Evidence, Burden of Proof and Finality, Cambridge: Cabridge University Press.

Garner, Bryan A (Eds). 1999. Black's Law Dictionary, Seventh Edition, St. Paul. Minn: West Group.

Soerjono Soekanto. 2008. Pengantar Penelitian Hukum. Jakarta: UI Press.

Soerjono Soekanto dan Sri Mamuji. 2007. Penelitian Hukum Normatif Suatu Tinjauan Singkat. Jakarta: RajaGrafindo Persada.

Raffensberger and Tickner. 1999. Introduction: To Foresee and Forestall, dalam Raffensberger et al (Eds), Protecting Public Health and the Environment: Implementing the Precautionary Principle, Washington DC: Island Press.

Van Dyke, Jon M. 2004. The Evolution and International Acceptance of the Precautionary Principle, dalam D.D. Caron and H.N. Scheiber (Eds), Bringing New Law to Ocean Water, Netherland: Koninklijke Brill NV.

\section{Jurnal:}

Ambrus, Monika. 2012. "The Precautionary Principle and a Fair Allocation of the Burden of Proof in International Environment Law", RECIEL, Vol. 21, Issue 3 (November 2012). 
Andorno, Roberto. 2004. "The Precautionary Principle: A New Legal Standard for a Technological Age", JIBL Vol. 01.

Cross, Frank. 1996. "Paradoxical Perils of the Precautionary Principle", 53 Wash. \& Lee L. Rev. 851, 851.

Ellis, Jaye. 2006. "Overexploitation of a Valuable Resource? New Literature on the Precautionary Principle." EJIL Vol. 17 No. 2.

Gundling, Lothar. 1990. "The Status in International Law of the Princple of Precautionary Action, 5 Int'l J. Estuarine \& Coastal L. 23, 30.

Hahn, Robert W. and Cass R. Sunstein. 2005. "The Precautionary Principle as a Basis for Decision Making", The Economists Voice, Vol. 2, Issue 2.

Hickey Jr, James E and Vern R. Walker. 1995. "Refining the Precautionary Principle in International Environmental Law", 14Va. Envtl.L.J.423.

Mandel, Gregory N. and James Thuo Gathii. 2006. "Cost-benefit Analysis versus the Precautionary Principle: Beyond Cass Sunstein's Laws of Fear. University of Illinois Law Review, Vol. 2006, No. 5.

Schomberg, René von. 2012. "The Precautionary Principle: Its Use Within Hard and Soft Law", EJRR, Vol. 2.

Steele, Katie. 2006. “The Precautionary Principle: A New Approach to Public Decision-making?", Law, Probability and Risk, Vol. 5.

Stone, Christopher D. 2001. "Is There a Precautionary Principle?", 31 Envtl. L. RPTR 10790.

Walker, Vern R. 1991. "The Siren Songs of Science: Toward a Taxonomy of Scientific Uncertainty for Decisionmakers”, 23 Conn.L. Rev.567, 572.

Bergkamp, Lucas. 2002. "Understanding the Precautionary Principle, 10(1) Environmental Liability 18.

\section{Internet:}

French National Advisory Committeee on Ethics. 2002. Ethical Issue Raised by the Development of ICSI (Opinion No. 75), 12 December 2002, tersedia dalam: http://www.ccne-ethique.fr/en/publications/ethical-questionsraised-development-icsi\#.Vp9j0Jp97IU [diakses tanggal 15 Desember 2015]. 
US Food and Drug Administration. 2001. PHS Guideline on Infectious Disease Issues in Xenotransplantation, tersedia dalam http://www.fda.gov/BiologicsBloodVaccines/GuidanceComplianceRegul atoryInformation/Guidances/Xenotransplantation/ucm074727.htm [diakses tanggal 15 Desember 2015].

UNESCO International Bioethics Committee (IBC). 2003. Report on Preimplantation Genetic Diagnosis and Germline Intervention, tersedia dalam: http://www.unesco.org.bioethics [diakses tanggal 15 Desember 2015].

Wingspread Statement. 1998. The Precautionary Principle, tersedia dalam: http//www.psrast.org/precaut.htm [diakses tanggal 20 Juli 2015].

\section{Perjanjian Internasional dan Peraturan Perundang-undangan:}

Paris Convention for the Prevention of Marine Pollution from Land-Based Sources 1974.

World Charter of Nature, UNGA Res. 37/7, U.N Doc. A/Res/37/7 (1982).

G.A.Res. 37/7, U.N. GAOR, 37th Sess., Supp. No. 15, at 17, U.N. Doc. A/37/51 (1982), reprinted in 22 I.L.M. 455 (1983).

Declaration on Protection of the North Sea, 1987.

Protocol on Substance that Deplete the Ozone Layer 1987 (Montreal Protocol)

Bamako Convention on Hazardous Wastes within Africa, 1991.

Convention on Climate Change 1992.

Convention for Protection of the Marine Environment of the Baltic Sea Area 1992 (Helsinki Convention)

Rio Declaration on Environment and Development, June 14, 1992, U.N. Doc. A/Conf.151/5/Rev.1.

Convention on Biological Diversity 1992.

WTO Agreement on the Application of Santary and Phytosanitary Measures 1994.

Cartagena Protocol on Biosafety 2000. 
Consolidate Act on Chemical Substance and Products (Consolidate Act of Denmark No. 583 of July 9, 1993).

Sweden Environmental Code of 1999.

the French Environmental Code of 2000. 